\title{
A Prospective Comparison of the 30-Minute and 60-Minute Oxytocin Dose Incremental Schedules for Induction of Labor at Term
}

Idowu P. ADE-OJO, Oluwafemi KUTI, Olabisi M. LOTO, Solomon O. OGUNNIYI, Dept. of Obs /Gyn, Obafemi Awolowo University Teaching Hospitals Complex, lle-lfe. Nigeria

\begin{abstract}
Aim: To compare the efficacy and safety of two oxytocin incremental protocols used for induction of labor in women of low parity.

Method: One hundred and twenty women (120) of low parity requiring induction of labour at term were randomly assigned into the two oxytocin induction dose protocols of the 30-minute and 60-minute incremental intervals. Induction-onset of labour interval, Induction-delivery interval, Delivery outcome and perinatal outcome were compared.

Results: The induction-onset of labour interval and the induction delivery interval were comparable between the 60-min group and the 30-min group. Intrapartum complications like fetal distress, uterine hyperstimulation and precipitate labour were more common in the 30-min group however, this was not statistically significant.

Conclusion: Oxytocin infusion regimens of 60-min and 30-min are comparable in outcome for induction of labour. The 60-min group carries less risk to both the mother and the fetus.
\end{abstract}

Keywords: Induction-delivery interval, Induction of labor, oxytocin

\section{Introduction}

Induction of labour is a common intervention during pregnancy in both the developed and developing countries $^{1,2}$. It is indicated in medical, obstetric and fetal conditions in which prolongation of the pregnancy would jeopardize fetal or maternal well being and in which there are no contraindications to vaginal delivery and the use of amniotomy, oxytocin and prostaglandin. A popular method of labour induction in term pregnancies is fore water amniotomy and synchronous oxytocin infusion ${ }^{3}$. This has been employed for more than fifty years ${ }^{4}$. Although prostaglandins are widely used for this purpose along with oxytocin in developed countries, oxytocin alone remains the major drug for medical induction in the developing nations ${ }^{5}$.

The half life of oxytocin in vivo is 3-10 minutes s.6 $^{5,6}$ and it is shorter when high doses are infused. In vivo studies have shown that a steady state concentration in plasma is reached at $40-60$ minutes $^{4,5}$.
Various regimens of oxytocin incremental intervals have been used for induction of labour. These vary from low dose-long interval (increase every 40-60minutes) to high dose-short interval (increase every 15-20 minutes) ${ }^{6}$.

Studies have shown that the 15-minute interval for increasing oxytocin dose after amniotomy may predispose to rapid oxytocin excess ${ }^{3}$. This is noted to be responsible for the complications that occurred in most reports. Studies comparing the oxytocin incremental intervals of 15 minutes and 30 minutes in women of low parity ${ }^{3}, 20$ minutes and 60 minutes in women of low parity ${ }^{7}$ and 15 minutes and 45 minutes in women of high parity ${ }^{8}$ have shown clearly that there is significant reduction in intrapartum complications and higher rates of vaginal delivery in the long interval groups.

The oxytocin dose incremental interval used in this environment is 30 minutes in women of low parity. This

\section{Correspondence}

Dr. Ade-Ojo IP, MD, FMCOG (Nig)

Lecturer Dept of Obs /Gyn

University Teaching Hospital, Ado-Ekiti, Nigeria.

Mobile: +2348033886173

E-mail: ipade_ojo@yahoo.com 
prospective study compared the 60 -minute with the 30-minute incremental intervals to see whether it will be safer without reducing the efficacy. The outcome of this study will go a long way in influencing practice in our environment.

\section{Methods}

This comparative study was carried out at the Obstetrics and Gynaecological Department of the Obafemi Awolowo University Teaching Hospitals Complex, Ile-Ife, Osun State, Nigeria, comprising two obstetric units of Ife Hospital Unit (IHU) and Wesley Guild Hospital (WGH) Ilesha from July 1, 2008 to June 30, 2009.

These hospitals serve as tertiary referral centres for secondary and primary tiers of hospitals in Ife-Ijesha, Ondo and Ekiti Zones of the country. The two obstetric units conduct an average of 2,150 deliveries every year and induction rate of $15.7 \%$.

It was a randomized clinical trial. The target population comprised of all pregnant women of low parity (Para $0,1,2$ and 3) at term (between 37 and 42 weeks) who have indications for induction of labour in the obstetric units of Ife Hospital Unit (IHU) Ile-Ife and Wesley Guild Hospital (WGH) Ilesha.

\section{Sample Size Determination}

An audit of labor induction in this institution using the labor ward records revealed that the incidence of failed induction was $21.4 \%$. This percentage was used to calculate the sample size using the formula:

$$
\mathrm{n}=\frac{1}{(1-\mathrm{f})} \quad \frac{\mathrm{x}\left[2 \times\left(\mathrm{Z}_{\alpha}+\mathrm{Z}_{\beta}\right)^{2} \times \mathrm{P} \times(1-\mathrm{P})\right]^{9,10}}{\mathrm{P}_{\mathrm{o}}-\mathrm{P}_{1}}
$$

Where $\mathrm{n}=$ minimum sample size $\mathrm{P}_{\mathrm{o}}=$ Incidence rate stated above which is $21.4 \%$ or 0.214 .

$\mathrm{P}_{1} \quad$ Proportion of participants in the 60-minute incremental interval group that is expected to exhibit the outcome of interest. This is usually set relative to $\mathrm{P}_{\mathrm{o}}$. For this study, I would like to determine if the failure rate of induction of labour would be reduced by $25 \%$ by using 60 minutes incremental interval of oxytocin infusion for induction of labour.

$$
\text { Then } \begin{array}{cc}
\mathrm{P}_{1}=\mathrm{P}_{\mathrm{o}}-\left(25 \times \mathrm{P}_{\mathrm{o}}\right) \\
\\
= & 0.2100-0.054 \\
= & 0.160
\end{array}
$$

$\mathrm{Z}_{\alpha} \quad$ determined from a statistical table based on the value of the level of significance $\alpha$. For this study, I am setting the level of significance at 0.05 then $Z_{\alpha}$
$=1.96$.

$Z_{\beta} \quad$ determined from a statistical table based on the acceptable power of comparison between the 2 groups. For this study a power of $90 \%$ was used $(0.90)$ with $Z_{\beta}=1.28$. $\mathrm{f}$ is the proportion of the subjects who are expected to be lost to follow up. For this study, $\mathrm{f}=0$. The sample size was approximated to be 60 patients for each of the study groups. Therefore 120 women admitted for induction of labour who met the inclusion criteria were randomly assigned to both $30-\mathrm{min}$ oxytocin infusion incremental interval which served as the control group and the 60-min oxytocin infusion incremental interval which was the experimental group.

\section{Inclusion Criteria}

Pregnant women of low parity, at term with singleton live fetuses in cephalic presentation admitted for induction of labour were counseled and after consenting were randomized to participate in the study. Gestational age was ascertained through reliable menstrual data for those that keep menstrual calendars and early ultrasound scan.

\section{Exclusion Criteria}

Women that were excluded from the study were those that had the following conditions: contracted pelvis, medical conditions in pregnancy, intrauterine growth restriction, antepartum hemorrhage, previous caesarean sections and those that refused to give consent.

\section{Allocation into groups}

Eligible patients were educated about the study and those who agreed to participate in the study were randomized to the two study groups on admission into the labour ward by opening a sealed envelope which had been arranged serially. Randomization was done using the method of block randomization using the random table generated numbers.

Those with unfavorable cervix had cervical ripening with transcervical extra-amniotic Foley's catheters, the balloons of which were inflated with $30 \mathrm{mls}$ of sterile water. Induction of labour was only commenced for those whose Bishop's Scores were at least 7.

Structured questionnaires were administered to obtain information about the personal data and other relevant information about the participants.

\section{0-minute oxytocin infusion incremental interval group}

This group had induction of labour with oxytocin base mixture of 5iu of oxytocin in 500mls of Ringer's lactate 
and oxytocin infusion was administered via primed intravenous giving set with size $20 \mathrm{G}$ cannula using gravity fed counting drops technique. The starting dose was $4 \mathrm{mu} / \mathrm{min}$ ( 8 drops) and increased every 30 minutes until adequate uterine contractions (defined as 3 contractions within 10 minutes lasting 40-60 seconds) were achieved or to a maximum of $32 \mathrm{mu} /$ $\min (64$ drops per minute)

\section{0-minute oxytocin infusion incremental interval group}

This group also had induction of labour with oxytocin base mixture of 5i.u of oxytocin in 500mls of Ringer's lactate and Oxytocin infusion was administered via primed intravenous giving set with size $20 \mathrm{O}$ cannula using gravity fed counting drops technique. The starting dose was $5 \mathrm{mu} / \mathrm{min}$ ( 8 drops/minutes) and increased every 60 minutes until there were adequate uterine contractions ( 3 contractions within 10 - minutes lasting 40-60seconds) or to a maximum of $32 \mathrm{mu} / \mathrm{min}$ (64 drops/minutes).

\section{Further management in labour}

Labour was monitored partographically to detect any abnormality in the progress of labour. The Pinnard stethoscope was used to monitor fetal heart tone every 15 minutes throughout labour.

Syntocinon produced by the same company (Novartis pharmaceutical) and procured from the central pharmacy store of the hospital was used for all the patients.

\section{Statistical Analysis}

Information obtained at the end of the study was processed using the computer soft ware Statistical Package for Social Science (SPSS) version 13. Frequency tables were made and results tested for significance using the student t-test for continuous variable and X2 for categorical variables with level of significance $(\mathrm{x})$ set at 0.05 .

\section{Ethical Consideration}

Ethical clearance was obtained for this study from the ethical clearance committee of the Obafemi Awolowo University Teaching Hospitals Complex, Ile-Ife. All participants were fully informed about the study and reserved their right to withdraw for whatever reasons at any stage of the study without any penalty.

\section{Scope and Limitation}

This study involved pregnant women of low parity (Para 0, 1, 2, 3) at term who had unambiguous indications for induction of labour and consented to participate in the study.

Excluded from the study were pregnant women of high parity (Para 4 and above), confirmed cases Intrauterine growth restrictions (IUGR), previous caesarean section(s), contraindications to vaginal delivery, those who refused to give consent.

The limitations of this study included the inability to use oxytocin infusion pump which could lead to variation in the oxytocin concentrations delivered per minute, by the gravity fed counting drops technique due to frequent changes in posture by the parturient. This is minimized by checking and normalizing the number of drops every five minutes and every time there was change in parturient position. Other limitations also included the inability to monitor labour using continuous electronic fetal heart rate monitoring and the inability to monitor intrauterine pressure.

\section{Results}

One hundred and twenty women were randomized into either the 60-minute or 30-minute oxytocin incremental dose for induction of labour. The consent of the women that participated in the study was obtained.

Table 1 shows the subjects' demographics. There were no significant differences demonstrated between the two groups with respect to mean maternal age, gestational age at delivery, parity and Bishop score.

\section{Table 1. Subjects Demographics}

\begin{tabular}{lccc}
\hline Parameters & 60-Min Group & 30-Min Group & P value \\
\hline & $\mathrm{n}=60$ & $\mathrm{n}=60$ & \\
& Mean \pm S.D. & Mean \pm S.D. & $27.50 \pm 3.10$ \\
Maternal age (years) & $29.81 \pm 4.66$ & $1.73 \pm 0.90$ & 0.796 \\
Parity & $1.83 \pm 1.03$ & $6.36 \pm 2.61$ & 0.079 \\
Bishop score & $7.83 \pm 0.72$ & $39.91 \pm 1.50$ & 0.591 \\
Gestational age (weeks) & $40.4 \pm 1.62$ & & 0.796 \\
\hline \hline
\end{tabular}


Table 2. Indication for induction of labour

\begin{tabular}{lll}
\hline Parameters & $\begin{array}{l}60-\text { Min Group } \\
\mathrm{n}=60(\%)\end{array}$ & $\begin{array}{l}30-\text { Min Group } \\
\mathrm{n}=60(\%)\end{array}$ \\
\hline $\begin{array}{l}\text { Prolonged pregnancy } \\
\quad \geq 42 \text { weeks) } \\
\begin{array}{l}\text { Premature rupture of } \\
\text { Membranes }\end{array}\end{array}$ & $41(68.3 \%)$ & $39(65.0 \%)$ \\
$\begin{array}{l}\text { Hypertension in Pregnancy } \\
\text { Unstable lie } \\
\text { (Stabilization induction) }\end{array}$ & $10(16.7 \%)$ & $12(20 \%)$ \\
\hline
\end{tabular}

Table 3. Temporal intervals

\begin{tabular}{llll}
\hline Parameters & $\begin{array}{l}\text { 60-Min Group } \\
n=60 \\
\text { Mean } \pm \text { S.D. }\end{array}$ & $\begin{array}{l}\text { 30-Min Group } \\
n=60 \\
\text { Mean } \pm \text { S.D. }\end{array}$ & P value \\
\hline Induction-onset of labour & $130.45 \pm 75.31$ & $93.33 \pm 64.89$ & 0.218 \\
interval (Min) & & & \\
Induction-delivery interval & $476.11 \pm 197.01$ & $520.00 \pm 243.46$ & 0.663 \\
\hline
\end{tabular}

Table 4. Delivery outcome

\begin{tabular}{|c|c|c|c|}
\hline Parameters & $\begin{array}{l}\text { 60-Min Group } \\
n=60(\%)\end{array}$ & $\begin{array}{l}\text { 30-Min Group } \\
n=60(\%)\end{array}$ & P value \\
\hline Vaginal delivery & $53(88 \%)$ & $51(85 \%)$ & \\
\hline Spontaneous & $50(83 \%)$ & 49 (81.3\%) & \\
\hline Assisted & $3(5 \%)$ & $2(3.3 \%)$ & \\
\hline Forceps & $1(1.7 \%)$ & - & \\
\hline Vacuum & $2(3.3 \%)$ & $2(3.3 \%)$ & \\
\hline Caesarean section & $7(12 \%)$ & $9(15 \%)$ & \\
\hline First stage & $5(8.3 \%)$ & $6(10 \%)$ & \\
\hline Second stage & $2(3.3 \%)$ & $3(5 \%)$ & \\
\hline \multicolumn{4}{|l|}{ Indications } \\
\hline Failure to progress & $5(8.3 \%)$ & $2(3.3 \%)$ & \\
\hline Fetal distress & $2(3.3 \%)$ & $7(12 \%)$ & \\
\hline Intrapartum complications & $5(8.3 \%)$ & $12(20 \%)$ & 0.051 \\
\hline Fetal distress & $2(3.3 \%)$ & $6(10 \%)$ & \\
\hline Uterine hyperstimulation & $3(5 \%)$ & $5(8.3 \%)$ & \\
\hline Precipitate labour & - & $1(1.7 \%)$ & \\
\hline
\end{tabular}


Table 5. Perinatal outcome

\begin{tabular}{llll}
\hline Parameter & $\begin{array}{c}\text { 60-Min Group } \\
\mathbf{n}=60 \\
\text { Mean } \pm \text { S.D. }\end{array}$ & $\begin{array}{l}\text { 30-Min Group } \\
\mathbf{n}=60 \\
\text { Mean } \pm \text { S.D. }\end{array}$ & P value \\
\hline Birth Weight in Kg & 3.27 & 3.12 & 0.334 \\
Apgar scores & & & \\
1 minute & $8.82 \pm 1.33$ & $8.18 \pm 2.35$ & 0.438 \\
\multicolumn{1}{c}{5 minute } & $10 \pm 0.00$ & $9.18 \pm 1.45$ & 0.08 \\
\hline
\end{tabular}

Table 2 summarizes the indications for the induction of labour which were comparable in the two study groups.

The temporal factors of labour are shown in table 3 . The mean induction - onset of labour interval was less in the 30-minute incremental interval group which was not statistically significant $(93.33 \pm 64.89$ minutes vs $130.45 \pm 75.31$ minutes, $p$-value 0.218 ). However, the induction - delivery interval was shorter in the 60-min group than the 30-min group. However, this also did not assume statistical significance.

Table 4 depicts the delivery outcome which was comparable in the two groups. Although not statistically significant, there were more intrapartum complications in the 30-min group than the 60-min group. Fetal distress, uterine hyperstimulation, and precipitate labour defined as induction delivery interval of three hours or less occurred less in the 60-min group.

The newborn outcome was also comparable in the two groups. There were no significant differences in the mean birth weight and the mean Apgar scores at one minute and five minutes respectively (table 5).

Except for one neonate in the 30-minute group who had severe birth asphyxia who promptly responded well to resuscitation, there were no maternal and perinatal deaths and no serious perinatal morbidity.

\section{Discussion}

The main aim of induction of labour is to achieve vaginal delivery with an optimum fetal outcome ${ }^{11}$. To achieve this, two major types of oxytocin infusion incremental interval protocols have been used. These include the high dose - short interval protocol (increase every $15-20$ minutes) and the low dose - long interval protocol (increase every $40-60$ minutes) ${ }^{6,12}$. Some workers had found higher rates of fetal distress and uterine hyperstimulation in parturient that had labour induced with the high dose - short interval protocol than the low dose - long interval protocol ${ }^{3,7,8,9,13}$.
In this study carried out among Nigerian women at the labour ward of the Obafemi Awolowo University Teaching Hospital complex, Ile-Ife, Nigeria, comparing the 30-min and 60-min oxytocin infusion incremental intervals for induction of labour in women of low parity. Subjects' demographics were similar in both groups; Mean maternal age was $(29.81 \pm 4.66$ vs. $27.50 \pm 3.10 ;$ p 0.175$)$, the mean gestational age was (40.4 \pm 1.62 vs. $39.91 \pm 1.50 ;$ p 0.591$)$ and the mean parity was $(1.73 \pm 0.90$ vs. $1.83 \pm 1.03$; p 0.796$)$.

The latent interval (which is the period to achieve adequate uterine contraction from the commencement oxytocin infusion) was shorter in the 30-min incremental group than the 60-min group, it was not statistically significant $(93.33 \pm 64.89$ minutes vs. $130.45 \pm 75.31$ minutes; $p$ 0.218). This is comparable to the study by Goni et $\mathrm{al}^{7}$. This shorter latent interval could be responsible for more intrapartum complications among the 30-min group. This findings further buttresses the finding by Amico et al that approximately forty minutes are required for any particular oxytocin dose to reach the steady state. ${ }^{7}$ Therefore, short incremental interval might lead to rapid oxytocin build-up and excess which could cause excessive stimulation of the myocytes thus leading to uterine hyperstimulation, fetal distress, precipitate labour and sometimes uterine rupture ${ }^{3,7,8,14}$. These intrapartum complications occur less frequently among the 60-minute group.

The induction delivery interval (IDI) was shorter among the 60-min group than the 30-min group but it was not statistically significant $(476.11 \pm 197.01$ minutes vs. $520.00 \pm 243.46$ minutes; p 0.663). Goni et al ${ }^{7}$ found a statistically significant shorter induction delivery interval in the 60-min group in a study that compared $20-\mathrm{min}$ and $60 \mathrm{~min}$ incremental interval. Orhue $^{3}$ found a statistically significant shorter induction delivery interval in the 30-min group in his comparison of the 15-min and 30-min incremental interval in women of low parity. Blackmore et $\mathrm{al}^{13}$ and Mercer et $\mathrm{al}^{9}$ also in two separate studies comparing 
15-min and 60-min found statistically significant shorter induction delivery interval in the 60 -min group. The shorter induction delivery interval in the 60-min group found in this study confirms the notion by other workers that the efficiency of uterine contractions on the outcome of labour when oxytocin is used for induction/augmentation of labour depends less on the base mixture (concentration) of oxytocin infusion, rate of increase whether arithmetic or geometric, but depends largely on the incremental interval ${ }^{3,8,12,14,15}$. The induction delivery interval in this study is not statistically different unlike the earlier studies. This may be due to the fact that very short intervals of 15 and 20 minutes were compared with 60 -minute in these earlier studies unlike the 30 minutes compared with 60-minute in this present study. This further shows that the longer the interval of increase, the better the outcome.

The mode of delivery was similar in both groups. $88 \%$ in the 60 -min group vs. $85 \%$ in the $30-\mathrm{min}$ group achieved vaginal delivery. Rate of caesarean section was also similar in both groups. Intrapartum complications attributable to oxytocin infusion occurred more frequently in the 30-min group than the 60 -min group but this was not statistically significant (20\% 30-min vs. 8.3\% 60-min; p 0.051). The 1-minute and 5-minute Apgar scores were both similar in the two groups.

This present study shows that both the 60 -min and the 30-min incremental oxytocin infusion regimes are comparable in achieving a safe outcome in induction of labour in women of low parity. However, the 60-min regimen is associated with safer outcome of labour with a lower risk to both the fetus and the mother. Although the better outcome in the 60-min regimen may not be statistically significant, it may be useful in the clinical settings particularly in most centres in our environment where facilities to monitor labour are limited. This is because of the difference in the intrapartum complications of $11.7 \%$ between the two groups.

\section{References}

1. Kwawukume EY. Induction and Augmentation of labour. In: Kwawukume EY, Emuveyan EE (eds). Comprehensive Obstetrics In The Tropics. Asante \& Hittscher Accra, Ghana 2002; 129-134.

2. Hofmeyr GJ, Alfirevic Z, Matonhodze B, Brocklehurst P, Cambell E, Nikodem VC. Titrated oral misoprostol solution for induction of
Labour: a multi-centre, randomized trial. British J Obstet Gynaecol 2001; 108: 952 - 959.

3. Orhue AAE. A randomized trial of 30-min and 15-min oxytocin infusion regimen for induction of labour at term in women of low parity. Int $\mathrm{J}$ Gynaecol Obstet 1993; 40: 219-225.

4. Dujardin B; Boutsen M, De Schampheleire I, Kulker R, et al. Oxytocics in developing countries. Int J Gynaecol Obstet 1995; 50: 243 -251 .

5. Zeeman GG, Khan-Dawood FS, Dawood MY. Oxytocin and its receptor in pregnancy and parturition: Current concept and clinical implications. J Obstet Gynaecol 1997; 89(5): $873-883$.

6. Xenakis EMJ, Piper MJ, Conway DL, Langer O. Induction of labour in the Nineties: Conquering the unfavorable cervix. J Obstet Gynaecol 1997; 90(2):235-239.

7. Goni S, Sawhney H, Gapalan S. Oxytocin induction of labour: a comparison of 20 - and 60 -min dose increment levels. Int J Gynaecol Obstet 1995; 48: 31-36.

8. Orhue AAE. A randomized trial of 45-minute and 15-minute increment infusion regimens for the induction of labour in women of high parity. $\mathrm{Br}$ J Obstet Gynaecol 1993; 126.

9. Mercer B, Pilgrim P, Sibai B. Labour induction with continuous low-dose oxytocin infusion. A randomized trial. Obstet Gynaecol 1991;77: 659.

10. Rouse DJ, Owen J, Hauth JC. Criteria for failed induction: Prospective evaluation of a standardized protocol. J Obstet Gynaecol 2000:96 (5pt 1):671-677.

11. Pooruma RR, Alka SG, Shashank VP. Preinduction cervical ripening an easier and safer alternative $-\mathrm{A}$ randomized study. Bombar Hospital Journal 2004; 46(3).

12. Gonser M. Labour induction and augmentation with oxytocin: Pharmacokinetics considerations. Achieves Obstet Gynaecol 1996; 256: 63 - 66.

13. Blakemore KJ, Petrie RH, Qin NG, et al. a prospective comparison of hourly and quarterhourly oxytocin dose increase interval for induction of labour at term. J Obstet Gynaecol 1990;75:757.

14. Orhue AAE: Induction of labour. Tropical J Obstet Gynaecol 1997; 14(1) 1-4

15. Durodola A, Kuti O, Orji EO, Ogunniyi SO. Rate of increase in Oxytocin dose on outcome of labour induction. Int J Gynecol Obstet. 2005; 90(2): $107-111$. 